\title{
Non-suppression of cortisol secretion by long term treatment with ketoconazole in patients with acute leukaemia
}

\author{
P DANDONA, J MOHIÚDDIN, HG PRENTICE* \\ From the Metabolic Unit, Department of Chemical Pathology and Human Metabolism, and *Department of \\ Haematology, Royal Free Hospital and School of Medicine, London NW3
}

SUMMARY Ketoconazole, a potent antifungal agent, inhibits adrenal steroidogenesis in normal subjects during short term treatment. Since this drug is used in the long term prophylaxis of fungal infections in patients with haematological malignancies, we have investigated whether such patients have evidence of adrenocortical suppression. Six patients on long term prophylaxis with ketoconazole were given tetracosactrin stimulation tests. All patients had high basal cortisol concentrations, which increased further after administration of $25 \mathrm{IU}$ of tetracosactrin. It is concluded that leukaemic patients receiving long term ketoconazole treatment do not have adrenocortical suppression. They may, in fact, have hyperstimulated adrenocortical function due to stress and hypovolaemia.

Ketoconazole is a potent antifungal agent which is used both for treatment of established fungal infections ${ }^{1}$ and for long term prophylaxis of such infections in immunocompromised patients. ${ }^{2}$ One major class of patients treated with this drug consists of those with acute leukaemia, ${ }^{2}$ who are treated with chemotherapeutic agents and total body irradiation. In view of the reports that this drug suppresses steroidogenesis by the adrenal gland ${ }^{3}$ and testes ${ }^{4}$ in normal subjects, we investigated the possibility that patients with acute leukaemia treated with this drug may have a progressive reduction in adrenal steroidogenesis and may therefore be vulnerable to addisonian crisis.

\section{Patients and methods}

Six patients undergoing treatment with ketoconazole were included in this study; three patients had acute myelobastic leukaemia, two had acute lymphoblastic leukaemia, and one had a non-Hodgkin's lymphoma. They were aged between 24 and 68 years (median 33 years). These patients were being treated with a variety of chemotherapeutic agents. Two patients had been given bone marrow transplants, but had had no overt gastrointestinal symptoms such as diarrhoea. The patients had

Accepted for publication 21 February 1985 been receiving ketoconazole ( $400 \mathrm{mg}$ daily) for between two and six weeks (median four and a half weeks).

A $24 \mathrm{~h}$ collection of urine was carried out for each patient for the measurement of urinary free cortisol. In addition, a short corticotrophin (Synacthen, Ciba) stimulation test was also carried out on all the patients: 25 IU of adrenocorticotrophin was injected after the collection of a venous blood sample in a heparinised glass tube. A second venous blood sample was collected 30 min later. The blood samples were centrifuged and the plasma was separated and frozen. Cortisol was measured in plasma and urine samples by a specific radioimmunoassay using a double antibody technique. All stimulation tests were carried out within $4 \mathrm{~h}$ of the last dose of ketoconazole.

\section{Results}

In three of the six patients $24 \mathrm{~h}$ urinary free cortisol secretion was greater than normal, while the remaining three had cortisol excretions within the normal range (Table). Basal plasma cortisol concentration was higher than normal in five of the six patients, and in one it was in the high normal range. After stimulation with adrenocorticotrophin the concentration of cortisol increased further; in all cases it 
Urinary free cortisol excretion and plasma cortisol concentrations before and after corticotrophin administration

\begin{tabular}{llll}
\hline $\begin{array}{l}\text { Patient } \\
\text { no }\end{array}$ & $\begin{array}{l}\text { Urinary free cortisol excretion } \\
(\text { nmol/24 } h)\end{array}$ & \multicolumn{2}{l}{ Plasma cortisol concentration (mmol/l) } \\
\cline { 2 - 4 } & & Before corticotrophin $\dagger$ & Afier corticotrophin $\ddagger$ \\
\hline 1 & 612 & 658 & 1112 \\
2 & 154 & 550 & 730 \\
3 & 269 & 350 & 890 \\
4 & 312 & 670 & 984 \\
6 & 418 & 784 & 916 \\
\hline
\end{tabular}

*Normal range 150 to $350 \mathrm{nmol} / 24 \mathrm{~h}$.

†Normal plasma cortisol range 200 to $650 \mathrm{nmol} / \mathrm{l}$.

$\ddagger$ After administration of Synacthen, cortisol must increase to $550 \mathrm{mmol} / \mathrm{l}$ or more.

was greater than $550 \mathrm{mmol} / \mathrm{l}$, the value considered to be normal in our laboratory. In none of the patients was either urinary free cortisol excretion or plasma concentration of cortisol below normal.

In three of the six patients urinary free cortisol and plasma cortisol $(9.00 \mathrm{am})$ measurements were also carried out before ketoconazole treatment. The urinary free cortisol excretion and plasma cortisol concentration were within the normal range in all three.

\section{Discussion}

These results show that leukaemic patients treated with ketoconazole in the long term do not have impaired cortisol secretion; this is borne out by both urinary excretion and plasma concentrations of cortisol before and after stimulation with corticotrophin. Since all stimulation tests were performed about $4 \mathrm{~h}$ after administration of ketoconazole, the possibility that the tests were carried out when plasma concentrations of this drug were low is unlikely. Furthermore, any significant, consistent decrease in cortisol secretion by the adrenal gland would have resulted in a reduction of urinary free cortisol.

Two of the patients included in this study had received bone marrow transplants. These patients develop graft versus host disease of their small intestine; this results in impaired absorption of ketoconazole and thus leads to erratic concentrations of this drug in plasma..$^{5}$ These two patients, however, had no overt diarrhoea or malabsorption. Furthermore, the various indices of cortisol secretion in them were no different from those in other leukaemic patients who had not had bone marrow transplants. Clearly, therefore, ketoconazole is a relatively safe drug as far as adrenocortical suppression in leukaemic patients is concerned. The theoretical risk of adrenocortical suppression hitherto shown in normal subjects has not been seen in patients with acute leukaemia. In fact, the presence of supranormal urinary free cortisol and basal plasma concentrations raises the possibility that the adrenal cortex in these patients is probably under a state of hyperstimulation. This may be secondary to the stress of their illness and also to marginal hypovolaemia due to hypoalbuminaemia, from which these patients often suffer. Needless to say, under such circumstances their requirement of cortisol is probably greater than normal. These data are also relevant to the use of this drug in other cases such as prostatic carcinoma, where total inhibition of testicular steroidogenesis is required. The doses of ketoconazole required for such inhibition (up to $1600 \mathrm{mg}$ daily) are much higher than those required for fungal infections, however, and would therefore pose a greater risk to adrenal steroid synthesis as well. ${ }^{6}$ Further investigation will be necessary to assess the safety of this drug in patients with prostatic carcinoma.

We thank Pamela Dale for preparing the manuscript.

\section{References}

' Hay R. Ketoconazole. Br Med J 1982;285:584-5.

${ }^{2}$ Hann IM, Prentice HG, Corringham R. Ketoconazole versus nystatin plus amphotericin B for fungal prophylaxis in severely immunocompromised patients. Lancet 1982; i:826-9.

${ }^{3}$ Pont A, Williams PL, Loose DS, et al. Ketoconazole blocks adrenal steroid synthesis. Ann Int Med 1982;97:370-2.

${ }^{4}$ Pont A, Williams PL, Azhar S, et al. Ketoconazole blocks testosterone synthesis. Arch Int Med 1982;142:2137-40.

s Hann I, Prentice HG, Keaney M, et al. The pharmacokinetics of ketoconazole in severely immunocompromised patients. J Antimicrob Chemother 1982;10:489-96.

- Allen JM, Kerle DJ, Ware H, Doble A, Williams G, Bloom SR. Combined treatment with ketoconazole and luteinising hormone releasing hormone analogue: a novel approach to resistant progressive prostatic cancer. Br Med J 1983;287: 1766 .

Requests for reprints to: Dr P Dandona, Director, Metabolic Unit, Department of Chemical Pathology and Human Metabolism, Royal Free Hospital, London, NW3 2QG UK, England. 